\title{
Coping strategies, stress, physical activity and sleep in patients with unexplained chest pain Margaretha Jerlock*1, Fannie Gaston-Johansson ${ }^{2}$, Karin I Kjellgren ${ }^{1}$ and Catharina Welin ${ }^{1}$
}

\author{
Address: ${ }^{1}$ Institute of Health and Care Sciences, The Sahlgrenska Academy, Göteborg University, Sweden and ${ }^{2}$ Johns Hopkins University, School \\ of Nursing, Baltimore, USA \\ Email: Margaretha Jerlock* - margaretha.jerlock@fhs.gu.se; Fannie Gaston-Johansson -fannie@son.jhmi.edu; \\ Karin I Kjellgren - karin.kjellgren@gu.se; Catharina Welin - catharina.welin@gu.se \\ * Corresponding author
}

Published: 31 October 2006

BMC Nursing 2006, 5:7 doi:10.1 186/1472-6955-5-7

This article is available from: http://www.biomedcentral.com/1472-6955/5/7

(C) 2006 Jerlock et al; licensee BioMed Central Ltd.

This is an Open Access article distributed under the terms of the Creative Commons Attribution License (http://creativecommons.org/licenses/by/2.0), which permits unrestricted use, distribution, and reproduction in any medium, provided the original work is properly cited.

\begin{abstract}
Background: The number of patients suffering from unexplained chest pain (UCP) is increasing. Intervention programmes are needed to reduce the chest pain and suffering experienced by these patients and effective preventive strategies are also required to reduce the incidence of these symptoms. The aim of this study was to describe general coping strategies in patients with UCP and examine the relationships between coping strategies, negative life events, sleep problems, physical activity, stress and chest pain intensity.
\end{abstract}

Method: The sample consisted of 179 patients younger than 70 years of age, who were evaluated for chest pain at the emergency department daytime Monday through Friday and judged by a physician to have no organic cause for their chest pain. The study had a cross-sectional design.

Results: Emotive coping was related to chest pain intensity $(r=0.17, p=0.02)$. Women used emotive coping to a greater extent than did men $(p=0.05)$. In the multivariate analysis was shown that physical activity decreased emotive coping (OR $0.13, \mathrm{p}<0.000 \mathrm{I}$ ) while sex, age, sleep, mental strain at work and negative life events increased emotive coping. Twenty-seven percent of the patients had sleep problems 8 tol 4 nights per month or more. Permanent stress at work during the last year was reported by $18 \%$ of the patients and stress at home by $7 \%$. Thirty-five percent of the patients were worried often or almost all the time about being rushed at work and $23 \%$ were worried about being unable to keep up with their workload. Concerning total life events, $20 \%$ reported that a close relative had had a serious illness and $27 \%$ had reasons to be worried about a close relative.

Conclusion: Our results indicated that patients with more intense UCP more often apply emotive coping in dealing with their pain. Given that emotive coping was also found to be related to disturbed sleep, negative life events, mental strain at work and physical activity, it may be of value to help these patients to both verbalise their emotions and to become cognizant of the influence of such factors on their pain experience. 


\section{Background}

Chest pain is one of the most common symptoms prompting individuals to seek acute care; however, more than half of the patients will not be judged to have chest pain of a cardiac origin [1,2]. In Sweden, this patient group has increased dramatically during the last fifteen years [3].

The unexplained chest pain (UCP) is often experienced for more than three months as was shown in two qualitative studies $[4,5]$ that included 20 subject each. The International Association for the Study of Pain (IASP) [6] makes a distinction between acute and chronic pain. The definition of chronic pain is based on duration of pain for three months or more. According to the IASP [6] definition of pain, UCP constitutes chronic pain.

Unexplained chest pain is complex and gives rise to feelings of fear and anxiety, uncertainty, stress and loss of strength. The chest pain often persists, resulting in long term physical limitations and impairment of daily activities $[4,5]$. Patients with constant pain, despite reassurance that they do not have heart disease, are known to have poor overall outcome in terms of symptom distress, disability, and continuing concern about heart disease. Karlson et al. [2] investigated symptoms and well being in an unselected patient group $(\mathrm{n}=1090)$ where acute myocardial infarction (AMI) was not confirmed, one year after discharge form hospital. They found that patients without AMI had more sleep problem, fatigue, chest pain, limitations in daily life than patients with confirmed AMI. Asbury et al. [7] compared women diagnosed with syndrome $X(n=100)$ and coronary heart disease $(n=100)$ and healthy controls $(\mathrm{n}=100)$ concerning anxiety, depression, social support and life events. The results showed that patients with syndrome $\mathrm{X}$ had more anxiety, were more depressed than controls and felt that their health interfered more with everyday life than women in the other two groups. However, there were no differences concerning life events. Lau et al[8] compared the occurrence of daily hassles and major life events in five groups of subjects ( 28 patients with atypical chest pain without gastro-oesophageal reflux, 20 with atypical chest pain and oesophageal reflux, 33 with dyspepsia, nine patients with obstructive airway disease, peptic ulcers and gallstone, and 33 healthy controls) and found that patients with atypical chest pain without underlying motility/reflux abnormalities had higher scores of negative life events and daily hassles than the other four groups.

Bradley et al [9] compared psychosocial factors in five groups of patients (24 patients with chronic UCP, 15 with irritable bowel syndrome (IBS), 32 with gastro-oesophageal reflux (GERD), 12 with coronary artery disease (CAD), and 21 healthy controls) and the results showed that patients with chronic UCP had a greater use of maladaptive strategies than patients with CAD and IBS. Cheng et al. [10] found in their study that the patients with UCP ( $\mathrm{n}=70$ ) used problem-focused strategies, but had an inflexible coping style compared to patients with rheumatism $(n=70)$ and healthy individuals $(n=70)$. Coping strategies in patients with chronic pain have been investigated by Hallberg et al. [11], who found that patients with fibromyalgia seem to interpret stressful situations as more threatening and to engage in more catastrophic thinking than do patients with work-related muscular pain. Woby et al. [12] investigated 90 patients with chronic back pain and found that patients with passive coping strategies, such as praying and hoping, evaluated the chest pain intensity to a higher level.

Sleep problems are a frequent complaint in patients with chronic pain. Sleep is important for health and is related to physical and emotional well-being. Hack and Mullington [13] investigated 40 individuals in a random controlled in-laboratory study. The results from this study showed that chronic insufficient sleep may affect health by bodily discomfort, fatigue, anger-aggression, body pain, stomach pain and backache. Asplund and Åhberg investigated women in a survey and showed a relationship between disturbed sleep and the occurrence of cardiac symptoms [14].

Since psychosocial factors are related to chest pain there is a need for treatments that complement customary medical care for UCP patients [15-18]. To date, systematic descriptions of psychosocial factors in UCP patients are lacking in the literature. Such investigations may provide important information for developing treatment strategies to decrease pain and improve quality of life in these patients.

The aim of this study was to describe general coping strategies in patients with UCP and examine the relationships between coping strategies, negative life events, sleep problems, physical activity, stress and chest pain intensity.

\section{Method}

Present study had a cross-sectional design and was carried out at Sahlgrenska University Hospital in Göteborg, Sweden from December 2002 to September 2003, with a fiveweek break in June-July. The study was approved by The Ethics Committee of Göteborg University, Sweden (Study code 169-02) and carried out in accordance with the Declaration of Helsinki.

\section{Study Sample}

Patients younger than 70 years of age who were evaluated for chest pain at the emergency department (ED) daytime Monday through Friday and judged by a physician to have 
no organic cause for the chest pain were included (i.e. gastro-oesophageal, cardiac or lung diseases were excluded). In total, 285 patients were eligible during the study period. Patients were excluded who 1) were identified for transfer to intensive care or were too ill to take part in the pain assessment or 2) had language difficulties. In total, 179 patients $(73.4 \%)$ participated in the study (table 1 ).

\section{Procedure}

All eligible patients were met by a nurse and assessed according to routines at the ED. Blood pressure, pulse, and a standard 12-lead electrocardiogram were taken and subsequently one of the two investigators in the research project asked the patients to participate in the study. The patients received both written and verbal information about all steps in the study from the investigator. After written informed consent was obtained, a pain assessment was performed on each patient by the investigator. The patients also filled in a questionnaire concerning psychosocial factors before discharge from ED.

\section{Pain assessment}

The Pain-O-Meter (POM) is based on the gate control theory [19] and is designed to assess the intensity, duration, location and quality of pain. In this study, pain intensity was assessed by using the100-mm vertical visual analogue scale (VAS) on the POM, with anchors of no pain at the bottom and excruciating pain at the top. The reliability and validity of the POM-VAS are well documented and a test-retest correlation of $\mathrm{r}=0.88(p<.001)$ has been reported for intensity ratings of the POM-VAS [20].

\section{Coping measurement}

According to Lazarus and co-workers [21], coping is a multidimensional process of cognitive and behavioural efforts to master, tolerate or reduce external and internal demands or conflicts created by stressful situations. They describe two main strategies, problem focused and emotion-focused strategies. Problem-focused coping is used when the problem is experienced as changeable and controllable. Emotion-focused coping is used when the situa- tion is uncontrollable and too difficult to handle and solve. The goal of this strategy is to relieve the emotional impact of stress and make the situation more tolerable [21].

Jalowiec Coping Scale (JCS) [22] was used to assess general coping strategies in order to find out if coping strategies were related to the chest pain intensity. This 40 -item questionnaire is based on Lazarus model of coping and was developed to cover and assess a wide range of coping behaviours. Jalowiec included a third concept, palliative coping which is a way of modulating tension and making the situation more tolerable or keeping it under control without directly taking care of the problem. Ten of the items in the subscale were previously classified as affective coping strategies and four as problem-oriented. Each item assesses how often a strategy is used to handle stress. Items are rated on a 4-point response scale ranging from never (1), sometimes (2), often (3) to almost always (4). The instrument assesses the variety of cognitive and behavioural strategies that subjects use to reduce stress. Factor analysis of the JCS has yielded a three-factor structure solution with three independent coping dimensions labelled confrontive coping (COS; 13 items, score range 13-52), emotive coping (EOS; 9 items, score range 9-36) and palliative coping (POS; 14 items, score range 14-56). Confrontive coping strategies focus on constructive handling of the stressful situation and facing up to the problem. Emotive coping strategies express emotions evoked by the situation. Jalowiec has comprehensively evaluated the construct validity of the JCS and has reported adequate internal consistency for the three factors (Cronbach's alpha 0.70-0.85) [22]. The instrument has been translated from English into Swedish and used in a Swedish patient population [23].

\section{Jenkins sleep scale}

Sleep problems were assessed using Jenkins Sleep Scale [24]. This questionnaire comprises 4 items rated on a 6step Likert scale, where 0 corresponds to no problems with sleep and 5 indicates sleep problems (scale score 0-

Table I: Study population. Participants and non-participants.

\begin{tabular}{|c|c|c|c|c|c|c|}
\hline & \multicolumn{2}{|c|}{ Men } & \multicolumn{2}{|c|}{ Women } & \multicolumn{2}{|c|}{ Total } \\
\hline & $\mathrm{n}$ & $(\%)$ & $\mathrm{n}$ & $(\%)$ & $\mathrm{n}$ & $(\%)$ \\
\hline Eligible & 166 & & 119 & & 285 & \\
\hline \multicolumn{7}{|l|}{ Excluded } \\
\hline Too ill & 2 & $(1.2)$ & 2 & $(1.7)$ & 2 & $(1.4)$ \\
\hline Language difficulties & 25 & (I5.I) & 12 & $(10.1)$ & 37 & (I3.0) \\
\hline Included & 139 & (83.7) & 105 & $(88.2)$ & 244 & $(85.6)$ \\
\hline Refused to participate & 10 & $(7.2)$ & 8 & $(7.6)$ & 18 & $(7.4)$ \\
\hline Administrative reasons $\mathrm{a}^{\mathrm{a}}$ & 28 & $(20.1)$ & 19 & $(18.1$ & 47 & $(19.3)$ \\
\hline Participants & 101 & (72.7) & 78 & (74.3) & 179 & $(73.4)$ \\
\hline
\end{tabular}

a Patients missing due to an overcrowded ED. 
20). The internal consistency of the sleep scale has been tested in a sample of British civil servants (Cronbach's alpha $=0.77$ ) [25] and in the present study the alpha value was 0.80 . The four items ask how often during the last month the subject has experienced the following: trouble falling asleep, trouble staying asleep, waking up several times per night, and waking up feeling tired and worn out after usual amount of sleep. The response alternatives are: not at all (0), 1-3 days (1), 4-7 days (2), 8-14 days (3), 15-21 days (4), 22-31 days (5). Patients are also asked to indicate their average number of hours sleep per night.

\section{Stress at home and at work}

Psychological stress was assessed with two questions related to stress at work and home. Stress was defined as feeling irritable, filled with anxiety or having sleep problems. The participants were asked to report how often they had felt stress on a 6-step scale: never experienced stress (0), experienced some period of stress (1), some period of stress in the last five years (2), several periods of stress in the last five years (3), permanent stress in the last year (4) and permanent stress in the last five years (5). A summary score is obtained by averaging the ratings from the two questions (scale score $=0-5$ ). These two questions are based on one single question combining stress at work and home used in numerous studies in Göteborg, Sweden, e.g. in a case-control study in 52 countries on psychosocial risk factors and acute myocardial infarction [26].

Mental strain at work was assessed with two questions: "How often do you worry about being rushed at work?" and "How often do you worry about keeping up with your workload" Ratings are made on 5-step response scale: never (1), seldom (2), sometimes (3), very often (4) and almost all the time (5). A summary score is obtained by summing the ratings of the two questions (range $=2-10$ ). These two questions have been used in a case-control study in patients with acute myocardial infarction [27] and Cronbach's alpha for the referents $(\mathrm{n}=412)$ was 0.91 for the scale. For the UCP patients in the present study, the Cronbach's alpha coefficient was 0.76 .

\section{Physical activity}

Physical activity in leisure time was assessed on a 4-step scale: sedentary (1) moderate physical (2) regular physical activity (3) and hard training or competitive sports (4) [28].

\section{Life events}

Negative life events were assessed in relation to the following 10 events: serious illness in a close relative; death of a close relative; worry about a close relative; divorce; forced to move to a new home: forced to change jobs; unemployment; insecurity at work; serious financial worries; an event leading to legal consequences. The response alternatives were: no (0); yes, earlier (1); yes, during the last year (2); yes, both during the last year and earlier (3) (scale score 0-30). The instrument has been used in patients with acute myocardial infarction [27].

\section{Statistical analysis}

All statistical analyses were performed in SAS (Statistical Analysis System) version 8.2 (SAS, Cary, NC, USA). Standard descriptive statistics were used. Spearman's correlation coefficient was used to evaluate relationships between selected psychosocial factors and chest pain intensity. P-value $<0.05$ was accepted as statistically significant. To test the internal consistency of the scales, Crohnbach's alpha was computed. Odds ratios were calculated by a logistic regression model in order to determine the relationship between coping strategies and demographics, sleep problems, life events, physical activity and mental strain at work.

\section{Results}

Of the 179 participating patients, $56.4 \%$ were men. The mean age for men was 44.2 (SD 13.0; range 19-67) and 46.6 (SD 13.3; range 17-69) for women. There was no significant age difference between men and women. Thirtyfour percent of the patients were immigrants; the average length of residence in Sweden was 23 years $(S D \pm 13)$ for men and 25 years $(S D \pm 14)$ for women. Patient characteristics are presented in table 2 . Table 3 shows mean, standard deviation and differences in men and women of the variables in the study.

\section{Prevalence of pain}

The patients were asked to indicate the intensity of their worst pain during the last 24 hours. The median value for chest pain intensity was 60 (range 5-100) in men and 70 (range 1-100) in women.

\section{Coping strategies}

There were no significant gender differences in the use of confrontive (COS) or palliative (POS) coping strategies, but women used emotive (ECS) coping strategies to a greater extent than did men $(p=0.05)$. Table 4 presents the most frequently endorsed items (rated sometimes, often, or almost always) in each of the coping strategies used by men versus women.

\section{Life events}

The most common life events in both men and women were those related to close relatives. Concerning total life events (last year and earlier), 20\% ( $\mathrm{n}=35)$ of the patients reported that a close relative had had a serious illness, $27 \%(n=49)$ had had reasons to be worried about a close relative and $11 \%(\mathrm{n}=19)$ reported that a close relative had died. 
Table 2: Demographic variables and traditional risk factors for ischemic heart disease in patients with UCP.

\begin{tabular}{|c|c|c|c|c|c|c|}
\hline \multirow[b]{2}{*}{ Variables } & \multicolumn{2}{|c|}{ Men $n=101$} & \multicolumn{2}{|c|}{ Women $n=78$} & \multicolumn{2}{|c|}{ Total $n=179$} \\
\hline & $\%$ & $(n)$ & $\%$ & $(n)$ & $\%$ & $(n)$ \\
\hline Single & 26 & (26) & 31 & (29) & 27 & (49) \\
\hline University education & 23 & (23) & 22 & (17) & 22 & $(40)$ \\
\hline Working full time or part time & 73 & (74) & 63 & (49) & 69 & (123) \\
\hline Sick leave during the last year & 25 & (25) & 29 & $(22)$ & 27 & $(47)$ \\
\hline Immigrant & 35 & (35) & 33 & $(25)$ & 34 & (60) \\
\hline Present smoker & 17 & (17) & 35 & (27) & 25 & (44) \\
\hline Sedentary in leisure time & 27 & (27) & 21 & (16) & 24 & (43) \\
\hline Body mass index $\geq 25$ & 70 & (69) & 45 & (34) & 59 & $(103)$ \\
\hline Diabetes & 5 & (5) & 10 & $(8)$ & 7 & $(13)$ \\
\hline Hypertension & 20 & (20) & 32 & $(25)$ & 26 & (45) \\
\hline $\begin{array}{l}\text { Myocardial infarction in one/ } \\
\text { both parents }\end{array}$ & 31 & (30) & 34 & (26) & 32 & (56) \\
\hline $\begin{array}{l}\text { Intake of analgesics, once a } \\
\text { week or more }\end{array}$ & II & $(10)$ & 11 & $(8)$ & 11 & (18) \\
\hline
\end{tabular}

\section{Stress at work/home}

Permanent stress at work during the last year was reported by $18 \%$ of the patients $(n=31)$ and during the last five years by $11 \%(n=20)$. Permanent stress at home during the last year was reported by $7 \%(n=13)$ and during the last five years by $8 \%(n=14)$.

Concerning mental strain at work, 35\% $(n=63)$ of the patients were worried often or almost all the time about being rushed at work and 23\% $(n=41)$ were worried about being unable to keep up with their workload.

\section{Sleep}

Twenty-seven percent ( $n=47)$ of the patients had sleep problems more than 14 nights per month (Jenkins sleep scale score $\geq 12$; range $0-20)$. Twelve percent $(n=22)$ of the patients slept 5 hours or less, 26\% $(n=47)$ slept 6 hours and $61 \%(n=109)$ slept 7 hours or more.

\section{Correlations between included variables}

Table 5 shows correlations between included variables. Emotive coping was correlated to all psychosocial factors. Negative life events were correlated to stress at home, sleep problems, palliative coping strategies and immigration. Sleep problems were correlated to negative life events, mental strain at work, stress at home and emotive coping.

\section{Relationships between coping strategies, psychosocial factors and chest pain intensity}

Spearman's correlation coefficient was used to evaluate univariate relationships between worst chest pain intensity in the last 24 hours, demographics and psychosocial factors. The only significant relationship was found between increased chest pain and emotive coping with a correlation of $\mathrm{r}=0.17(p=0.02)$.

Table 3: Mean (SD) and differences in men and women with UCP.

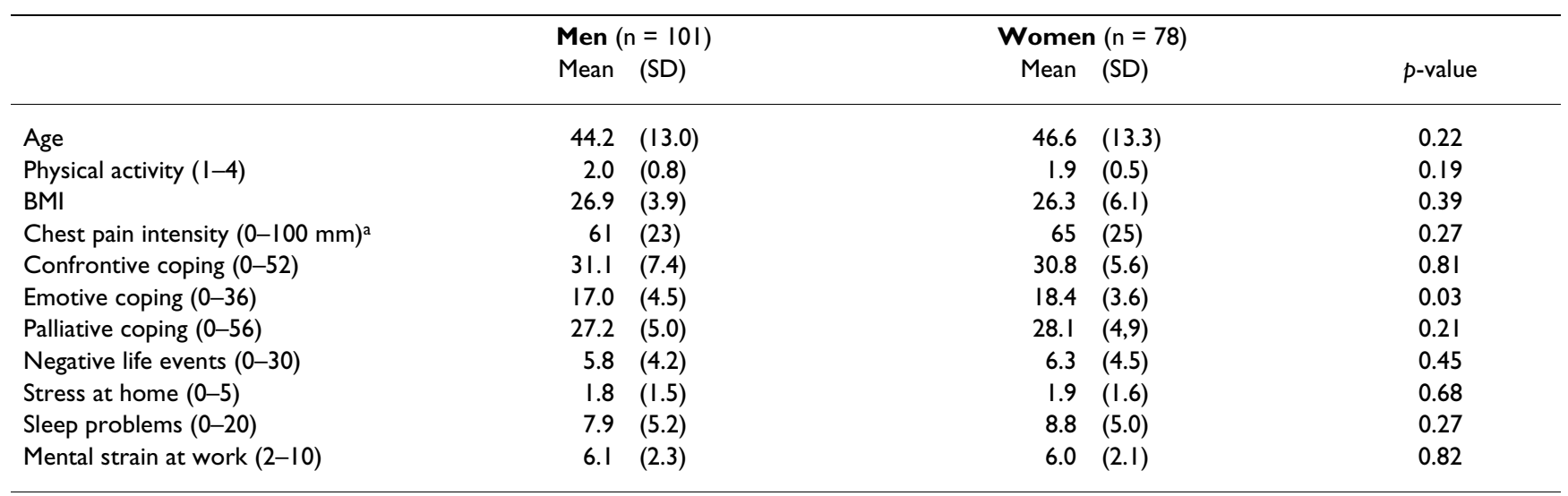

aDuring the last 24 hours 
Table 4: Coping strategies in patients with UCP. The most frequency items, and items with gender differences.

\begin{tabular}{|c|c|c|c|c|c|}
\hline & \multicolumn{2}{|c|}{ Men $(n=101)$} & \multicolumn{2}{|c|}{ Women $(n=78)$} & \multirow[b]{2}{*}{$p$-value } \\
\hline & $\%$ & (n) & $\%$ & $(n)$ & \\
\hline \multicolumn{6}{|l|}{ CONFRONTIVE COPING (I 3 items $\left.{ }^{\mathrm{a}}\right)$} \\
\hline \multicolumn{6}{|l|}{ Most frequent ${ }^{\mathrm{b}}$} \\
\hline Think through different ways to manage the situation & 92 & (91) & 100 & $(72)$ & 0.01 \\
\hline Try to keep the situation under control & 95 & (92) & 93 & $(65)$ & 0.59 \\
\hline Actively try to change the situation & 88 & (85) & 96 & $(66)$ & 0.11 \\
\hline Try to look at the problems objectively and see all sides & 87 & (84) & 92 & $(65)$ & 0.31 \\
\hline Try out different ways of solving the problems & 84 & (82) & 94 & $(65)$ & 0.05 \\
\hline Try to find out more about the situation & 79 & (77) & 91 & (63) & 0.04 \\
\hline \multicolumn{6}{|l|}{ Significant gender differences ${ }^{b}$} \\
\hline Seek support from family or friends & 66 & (65) & 86 & $(63)$ & 0.002 \\
\hline \multicolumn{6}{|l|}{ EMOTIVE COPING ( 9 items ${ }^{\mathrm{a}}$ ) } \\
\hline \multicolumn{6}{|l|}{ Most frequent ${ }^{\mathrm{b}}$} \\
\hline Worry & 95 & (94) & 100 & (75) & 0.05 \\
\hline Get nervous & 77 & (76) & 96 & $(70)$ & 0.001 \\
\hline Take off by myself, want to be alone & 72 & (7I) & 84 & $(62)$ & 0.06 \\
\hline \multicolumn{6}{|l|}{ Significant gender differences ${ }^{\mathrm{b}}$} \\
\hline Get angry & 50 & (50) & 72 & $(52)$ & 0.004 \\
\hline Eat, smoke, chew gum & 49 & (49) & 68 & $(50)$ & 0.02 \\
\hline \multicolumn{6}{|l|}{ PALLIATIVE COPING (I4 itemsa) } \\
\hline \multicolumn{6}{|l|}{ Most frequent ${ }^{\mathrm{b}}$} \\
\hline Hope for improvement & 93 & (92) & 96 & (7I) & 0.40 \\
\hline Accept the situation as it is & 90 & (88) & 90 & $(61)$ & 0.98 \\
\hline Try to put the problems out of my mind & 90 & (89) & 94 & $(69)$ & 0.27 \\
\hline Laugh it off and think things could have been worse & 85 & (83) & 90 & $(65)$ & 0.28 \\
\hline Settle for the next best thing to what I really want & 74 & (72) & 80 & $(55)$ & 0.41 \\
\hline \multicolumn{6}{|l|}{ Significant gender differences ${ }^{b}$} \\
\hline Resign because things look hopeless & 50 & (49) & 71 & (49) & 0.01 \\
\hline Pray and trust in God & 34 & (34) & 44 & $(32)$ & 0.20 \\
\hline Resign because it is fate & 34 & (33) & 47 & $(32)$ & 0.08 \\
\hline \multicolumn{6}{|l|}{ OTHER $\left(4\right.$ items $\left.{ }^{\mathrm{a}}\right)$} \\
\hline Cryb & 30 & (30) & 81 & $(60)$ & $<0.0001$ \\
\hline Drink alcoholb & 44 & (43) & 38 & $(28)$ & 0.43 \\
\hline Meditate, use yoga or other relaxationb & 20 & (19) & 40 & $(28)$ & 0.004 \\
\hline Take medication to reduce tension ${ }^{b}$ & 18 & (18) & 19 & $(14)$ & 0.86 \\
\hline
\end{tabular}

aResponse alternatives: Never, Sometimes, Often, Almost always

bSometimes, Often or almost always 
Odds ratios were calculated by a logistic regression model. Univariate and multivariate analysis were conducted to investigate how emotive coping was related to demographics and psychosocial variables in the study. Emotive coping was negatively related to physical activity (OR $0.13, p<0.0001)$ and positively to sex, age, sleep, mental strain at work and negative life events (Table 6).

\section{Discussion}

Our patients used confrontive strategies in stress situations, but the results suggest that they had difficulties to handle stress-related emotions, which affect the chest pain intensity. The results showed that there was a relationship between emotive coping and chest pain intensity. Our results also showed that negative life events and mental strain at work and sleep problems were positively related to emotive coping while physical activity was negative related to emotive coping. It may therefore be of great value to focus on emotional responses to stress in UCP patients and to help these patients to verbalise their emotions and to become cognizant of the psychosocial influences on the pain experience.

Similar results to our own were reported by Raak and Wahren [29] in women with headache e.g. patients who had experienced headache during the previous three months more frequently used emotive coping strategies than those with no headache during the same period.

Our multivariate analysis showed that physical activity independently predicted the use of emotive coping, where more physical activity was associated with less use of emotive coping. More than half of the patients had BMI $\geq 25$ and improved physical activity could probably help these patients in losing weight. We know from previous research that physical activity reduces risk for ischemic heart disease (IHD) and Wilhelmsen et al. [30] have shown that patients with unspecific chest pain are at increased risk of dying from coronary heart disease. Improving physical activity in this patient group may decrease emotive coping and by that the chest pain intensity as well as risk factors for IHD.

Tyni-Lenne [31] investigated the effects of physical training in 24 women with syndrome $\mathrm{X}$ and found that the women benefit from exercise capacity and quality of life. In a previous qualitative study by Jerlock et al. [5], patients with UCP stated that they did not exercise because they were uncertain about how much they could exert themselves with their undiagnosed chest pain.

Sleep was also found to be related to emotive coping. In a study by Welin et al[32], $7 \%$ of men and $20 \%$ of women referents scored $\geq 12$ on the Jenkins Sleep Scale, which is much less than among our UCP patients $(27 \%)$. In a sur- vey with 3669 randomly selected women, Asplund and Åberg [33] showed that all types of sleep disturbances, such as difficulty in falling asleep, early awakening and nightmares, increase the risk of cardiac symptoms as spasmodic chest pain and irregular heart beats. Less than $5 \mathrm{~h}$ sleep was associated with twofold increase in spasmodic chest pain.

Sedentary in leisure time and sleep problems were related to emotive coping and may therefore be important factors to pay attention to in efforts to alleviate chest pain. Studies have shown that regular exercise, such as walking, improves sleep $[34,35]$. In the above mentioned study by Jerlock et al[5], patients viewed walking as a safe form of exercise and walked long distances without problems. In intervention programmes, it is important that the patients be taught about the chest pain itself and how to handle situations to ensure that the patients feel secure when exercising.

Many UCP patients suffer from their symptoms for a long time $[4,5]$. In discussing the relationship between sleep and chronic pain, Roehrs and Roth [36] and Smith and Haythornthwaite [37] have pointed out that this relation is bidirectional and therefore treatment has to focus on both pain and sleep problems. Thirty-eight percent of our UCP patients reported 6 hours sleep or less per night. Roehrs et al. [38] conducted a study with a two repeateddesign in a sleep laboratory. Thirteen pain-free individuals participated and the result showed that even modest shortened sleep produces hyperalgesia the following day.

The number of patients suffering from UCP is increasing and, correspondingly, the costs for caring for these patients are escalating, since many of them are admitted to the emergency ward overnight to rule out cardiac causes to the pain. It is therefore important to develop not only effective treatment strategies to reduce the suffering experienced by these patients, but also preventive strategies to reduce the costs for society.

The main limitation of the present study is its cross-sectional design which only assesses the use of coping strategies at only one point in time. The data were also collected at a single hospital at daytime, which means that our results are not generalisable to patients who seek care at night. In order to further explore the influence of psychosocial factors on UCP, we plan to conduct a case-control study comparing patients with UCP with a referent group to determine if patients with UCP differ from a healthy population regarding psychosocial factors.

\section{Implications for clinical practice}

There is a lack of intervention studies concerning UCP patients which can be explained by a gap in the knowl- 
Table 5: Correlations between included variables among patients with unexplained chest pain $(\mathrm{n}=\mathbf{1 7 9})$.

\begin{tabular}{|c|c|c|c|c|c|c|c|c|c|c|c|c|c|c|c|c|}
\hline & & 2. & 3. & 4. & 5. & 6. & 7. & 8. & 9. & 10 & II. & 12. & 13. & 14. & 15. & 16. \\
\hline 1. & Single & -0.04 & -0.07 & -0.04 & 0.03 & -0.05 & -0.07 & -0.02 & -0.04 & $0.16 *$ & -0.03 & -0.02 & -0.13 & 0.11 & -0.02 & 0.19 \\
\hline 2. & $\begin{array}{l}\text { University } \\
\text { education }\end{array}$ & & -0.13 & -0.62 & 0.01 & -0.14 & $0.23 * *$ & -0.12 & -0.05 & $0.25^{* *}$ & $-0.17^{*}$ & -0.12 & -0.11 & -0.00 & -0.11 & 0.11 \\
\hline 3. & $\begin{array}{l}\text { Working } \\
\text { full timel } \\
\text { part time }\end{array}$ & & & 0.00 & $0.20 * *$ & -0.88 & -0.03 & 0.09 & 0.11 & 0.08 & 0.14 & $0.26 * *$ & $0.15^{*}$ & 0.13 & 0.04 & $0.17^{*}$ \\
\hline 4. & $\begin{array}{l}\text { Sick leave } \\
\text { the last year }\end{array}$ & & & & 0.03 & 0.12 & 0.09 & 0.09 & 0.08 & -0.06 & 0.04 & 0.06 & 0.13 & $0.15^{*}$ & 0.09 & -0.01 \\
\hline 5. & Immigrant & & & & & -0.03 & $0.16 *$ & 0.06 & 0.11 & -0.02 & $0.16 *$ & $0.35 * *$ & -0.02 & $0.24 * *$ & 0.12 & $0.21 * *$ \\
\hline 6. & $\begin{array}{l}\text { Present } \\
\text { smoker }\end{array}$ & & & & & & $-0.31 * *$ & $-0.16 *$ & $0.23 * *$ & -0.07 & $0.20 *$ & 0.08 & $0.16^{*}$ & 0.05 & 0.12 & -0.02 \\
\hline 7. & $\begin{array}{l}\text { Physical } \\
\text { activity }\end{array}$ & & & & & & & -0.11 & -0.06 & $0.19 *$ & $-0.37^{* *}$ & 0.04 & -0.08 & 0.03 & $-0.23 * *$ & -0.03 \\
\hline 8. & BMI & & & & & & & & -0.02 & 0.02 & $0.17 *$ & 0.02 & 0.06 & 0.06 & $0.18^{*}$ & 0.13 \\
\hline 9. & $\begin{array}{l}\text { Chest pain } \\
\text { intensity }\end{array}$ & & & & & & & & & -0.05 & $0.17^{*}$ & 0.07 & 0.13 & 0.11 & 0.02 & -0.02 \\
\hline 10. & $\begin{array}{l}\text { Confrontive } \\
\text { coping }\end{array}$ & & & & & & & & & & -0.12 & 0.11 & -0.8 & $0.18^{*}$ & -0.35 & 0.02 \\
\hline II. & $\begin{array}{l}\text { Emotive } \\
\text { coping }\end{array}$ & & & & & & & & & & & $0.43^{* *}$ & $0.36 * *$ & $0.30 * *$ & $0.35^{* *}$ & $0.30 * *$ \\
\hline 12. & $\begin{array}{l}\text { Palliative } \\
\text { coping }\end{array}$ & & & & & & & & & & & & 0.14 & $0.17^{*}$ & 0.16 & 0.14 \\
\hline 13. & $\begin{array}{l}\text { Sleep } \\
\text { problems }\end{array}$ & & & & & & & & & & & & & $0.26 * *$ & $0.18^{*}$ & $0.22 * *$ \\
\hline 14. & $\begin{array}{l}\text { Negative life } \\
\text { events }\end{array}$ & & & & & & & & & & & & & & 0.15 & $0.26 * *$ \\
\hline 15. & $\begin{array}{l}\text { Mental } \\
\text { strain at } \\
\text { work }\end{array}$ & & & & & & & & & & & & & & & $0.28 * *$ \\
\hline 16. & $\begin{array}{l}\text { Stress at } \\
\text { home }\end{array}$ & & & & & & & & & & & & & & & \\
\hline
\end{tabular}

aDuring the last 24 hours

$*<0.05 * *<0.01$

Table 6: Univariate and multivariate relationships between emotive coping strategies and psychosocial variables in patients with UCP $(n=179)$.

\begin{tabular}{|c|c|c|c|c|c|c|}
\hline \multirow[b]{3}{*}{ Variables } & \multicolumn{6}{|c|}{ Emotive coping } \\
\hline & \multicolumn{3}{|c|}{ Univariate } & \multicolumn{3}{|c|}{ Multivariate ${ }^{\mathrm{a}}$} \\
\hline & OR & $(95 \% \mathrm{Cl})$ & $p$-value & OR & $(95 \% \mathrm{Cl})$ & $p$-value \\
\hline Sex (female) & 4.07 & $(1.12-14.79)$ & 0.03 & 3.39 & $(1.01-11.40)$ & 0.005 \\
\hline Age & 0.94 & $(0.90-0.99)$ & 0.02 & 0.93 & $(0.88-0.97)$ & 0.004 \\
\hline Single $(0-1)$ & 1.17 & $(0.28-4.93)$ & 0.83 & & & \\
\hline University education $(0-1)$ & 0.34 & $(0.07-1.63)$ & 0.17 & & & \\
\hline Immigrants $(0-1)$ & 0.31 & $(0.08-1.19)$ & 0.08 & & & \\
\hline Physical activity (I-4) & 0.08 & $(0.04-0.21)$ & $<0.0001$ & 0.13 & $(0.06-0.32)$ & $<0.0001$ \\
\hline Sleep problems (0-20) & 1.35 & $(1.20-1.5 I)$ & $<0.0001$ & 1.25 & $(1.11-1.42)$ & 0.0002 \\
\hline Mental strain at work $(2-10)$ & 2.00 & $(1.48-2.70)$ & $<0.0001$ & 1.44 & $(1.08-1.91)$ & 0.005 \\
\hline Stress at home $(0-5)$ & 2.17 & $(1.43-3.29)$ & 0.0003 & 1.15 & $(0.74-1.77)$ & 0.89 \\
\hline Life events $(0-30)$ & 1.29 & $(1.12-1.49)$ & 0.0006 & 1.21 & $(1.04-1.41)$ & 0.01 \\
\hline
\end{tabular}

aOnly significant $(p<0.05)$ variables in the unvariate analysis are included. 
edge about this patient group, but also by difficulties to find robust methods to reduce biasis and to enhance the generalizability of the findings. Esler and Bock [18] describe the current state of treatment for non-cardiac chest pain (NCCP) and recommend a brief intervention which is able to reduce the frequency of NCCP. They recommend a bio-psychosocial model based on the knowledge that almost all illnesses are influenced by biological, psychological and social factors and propose that better outcomes are achieved when therapeutic interventions take into account the relationships between these factors. They suggest that treatment must focus on educating the patients to manage their chest pain symptoms, cardiac risk factors and stress.

Based on the results from this study, an intervention programme with a bio-psychosocial model could be appropriate in order to enhancing the patients coping ability since the emotive coping style seems to increase the chest pain intensity. A programme, containing education about chest pain, improved awareness about own coping strategies and reactions on stress situations, and the importance of physical activity could be valuable to decrease pain and improve the quality of life for these patients.

Intervention programmes should be designed to be applicable to the entire UCP patient group, but implemented in such a way that the needs of the individual patient are met. This means that the nurse must listen to how the patient describes and manages everyday life and promote communication conducive to learning [39].

\section{Conclusion}

Our results indicate that the intensity of unexplained chest pain is related to emotive coping, where patients with more intense UCP more often apply emotive coping in dealing with their pain. Given that emotive coping was also found to be related to negative life events, mental strain at work, disturbed sleep and physical activity, it may be of value to help these patients to both verbalise their emotions and to become cognizant of the influence of such factors on their pain experience.

\section{Competing interests}

The author(s) declare that they have no competing interests.

\section{Authors' contributions}

$\mathrm{MJ}$ contributed in all stages of the research: planning, data collection and analyses, and in writing the bulk of the paper. FG-J initiated the research project. KK contributed in the analyses and writing. CW contributed in all stages of the research project. All authors have read and approved the final manuscript.

\section{Acknowledgements}

The study was supported by grants from the Swedish Heart and Lung Foundation (20060162).

\section{References}

I. Eslick GD, Talley NJ: Non-cardiac chest pain: predictors of health care seeking, the types of health care professional consulted, work absenteeism and interruption of daily activities. Aliment Pharmacol Ther 2004, 20(8):909-915.

2. Karlson BW, Wiklund I, Bengtson A, Herlitz J: Prognosis, severity of symptoms and aspects of well-being among patients on whom myocardial infarction was ruled out. Clin Cardiol 1994, I7:427-431.

3. Murphy NF, Maclntyre K, Capewell S, Stewart S, Pell J, Chalmers J, Redpath A: Hospital discharge rates for suspected acute coronary syndromes between 1990 and 2000: Population based analysis. $B M] 2004,12: 14|3-14| 4$.

4. Janson Fagring A, Gaston-Johansson F, Danielson E: Description of unexplained chest pain and its influence on daily life in men and women. Eur J Cardiovasc Nurs 2005, 4:337-344.

5. Jerlock M, Gaston-Johansson F, Danielson E: Living with unexplained chest pain. J Clin Nurs 2005, 14:956-964.

6. IASP: Classification of chronic pain. Edited by: ed. . Seattle, International Association for the Study of Pain, IASP,; 1994.

7. Asbury EA, Creed F, Collins P: Distinct psychosocial differences between women with coronary heart disease and cardiac syndrome X. Eur Heart J 2004, 25(19): 1695- I70I.

8. Lau GK, Hui WM, Lam SK: Life events and daily hassles in patients with atypical chest pain. Am J Gastroenterol 1996, 91(10):2157-2162.

9. Bradley LA, Richter JE, Scarinci IC, Haile JM: Psychosocial and psychophysical assessments of patients with unexplained chest pain. Am J Med 1992, 92:65-73.

10. Cheng C, Wong WM, Lai KC, Wong BCY, Hu WHC, Hui WM, Lam SK: Psychosocial factors in patients with noncardiac chest pain. Psychosom Med 2003, 65:443-449.

II. Hallberg LRM, Carlsson SG: Anxiety and coping in patients with chronic work-relate muscular pain and patients with fibromyalgia. Eur J Pain 1998, 2:309-319.

12. Woby SR, Watson PJ, Roach NK, Urmston M: Coping strategy use: Does it predict adjustment to chronic back pain after controlling for catastrophic thinking and self-efficacy for pain control. J Rehabil Med 2005, 37:100-107.

13. Haack $M$, Mullington JM: Sustained sleep restriction reduces emotional and physical well-being. Pain 2005, I | 9:56-64.

14. Asplund $\mathrm{R}$, Åberg $\mathrm{H}$ : Sleep and cardiac symptoms amongst women aged 40-64 years. J Intern Med 1998, 243:209-2I3.

15. Mayou RA, Bass CM, Bryant BM: Management of non-cardiac chest pain: from research to clinical practice. Heart 1999, 8I:387-392.

16. Mayou RA, Thompson DR: Treatment needs of patients admitted for acute chest pain. J Psychosom Res 2002, 53: I I77-I I 83.

17. Esler JL, Barlow DH, Woolard RH, Nicholson RA, Nash JA, Erogul $\mathrm{MH}$ : A brief-cognitive behavioural intervention for patients with noncardiac chest pain. Behav Ther 2003, 34: I29-1 48.

18. Esler JL Bock, B.C: Psychological treatments for noncardiac chest pain. Recommendations for a new approach. J Psychosom Res 2004, 56:263-269.

19. Melzack R, Wall PD: Pain mechanisms: A new theory. Science 1965, I50:97I-978.

20. Gaston-Johansson F: Measurement of pain: The psychometric properties of Pain-O-Meter, a simple, inexpensive pain assessment tool that could change health care practices. J Pain Symptom Manage 1996, I 2:172-182.

21. Lazarus RS, Folkman S: Stress, Appraisal, and Coping. New York , Springer; 1984.

22. Jalowiec A: Confirmatory factor analysis of the Jalowiec Coping scale. In Measurement of nursing outcomes: Nursing client outcomes Volume Vol I. Edited by: Walz CSO. New York , Springer; 1988:287-308.

23. White M, Elander G: Translation of an instrument - The USNordic Family Dynamics Nursing Research Project. Scand J Caring Sci 1992, 6:161-164. 
24. Jenkins CD, Stanton BA, Niemcryk SJ, Rose RM: A scale for the estimation of sleep problems in clinical research. J Clin Epidemiol I 988, 41:313-32I.

25. Nasermoaddeli A, Sekine M, Kumari M, Chandola T, Marmot M, Kagamimori S: Association of sleep Quality and free time leisure activities in Japanese and British civil servants. J Occup Health 2005, 47:384-390.

26. Rosengren A, Hawken S, Öunpuu S, Silwa K, Zubaid M, Almahmeed W, Blacket N, Sitthi-amorn C, Sato H, Yusuf SINTERHEART: Association of psychosocial risk factors with risk of acute myocardial infarction in II II9 cases and 13648 controls from 52 countries (the INTERHEART study): case-control study. The Lancet 2004, 364:364: 953-962.

27. Welin CLM, Rosengren A, Wedel H, Wilhelmsen L: Myocardial infarction in relation to work, family, and life events. Cardiovascular Risk Factors 1995, 5:30-38.

28. Rosengren A, Hawken S, Ounpuu S, Sliwa K, Zubaid M, Almahmeed WA, Blackett KN, Sitthi-amorn C, Sato H, Yusuf S: Association of psychosocial risk factors with risk of acute myocardial infarction in IIII9 cases and 13648 controls from 52 countries (the INTERHEART study): case-control study. Lancet 2004, 364(9438):953-962.

29. Raak R, Wahren LK: Headache and coping in a female working population. Scand J Caring Sci 2005, 1 9:325-329.

30. Wilhelmsen L Rosengren, A., Hagman, M., Lappas, G: "Nonspecific" Chest Pain Associated with High Long-Term Mortality:. Clin Cardiol 1998, 21:447-482.

3I. Tyni-Lenne R, Stryjan S, Eriksson B, Berglund M, Sylven C: Beneficial therapeutic effects of physical training and relaxation therapy in women with coronary syndrome $\mathbf{X}$. Physiother Res Int 2002, 7(I):35-43.

32. Welin C Rosengren, A., Wilhelmsen, L: Behavioral characteristics in patients with myocardial infarction- a case contol study. Cardiovasc Risk 1995, 2:247-254.

33. Asplund $\mathrm{R}$, Åberg $\mathrm{H}$ : Sleep and cardiac symptoms amongst women aged 40-64 years. J Inter Med 1998, 243:209-2I3.

34. Sherrill DL, Kotchou K, Quan SF: Association of physical activity and human sleep disorders. Arch Intern Med 1998, I 58(I7): I894-1898.

35. Wilbur JE, Miller AM, McDevitt J, Wang E, Miller J: Menopausal status, moderate-intensity walking, and symptoms women. Res Theory Nurs Pract 2005, 19:163-180.

36. Roehrs T, Roth T: Sleep and pain: interaction of two vital functions. Semin Neurol 2005, 25:106-1 I6.

37. Smith MT, Haythornthwait JA: How do sleep disturbances and chronic pain inter-relate? Insights from the longitudinal and cognitive-behavioral clinic trials literature. Sleep Med Rev 2004, 8: II9-132

38. Roehrs T, Hyde M, Blaisdell B, Greenwald M, Roth T: Sleep loss and REM sleep loss are hyperalgesic. Sleep 2006, I:| |45-|5|.

39. Skott C: Caring narratives and the strategy of presence, Narrative communication in nursing practice and research. Nurs Sci Q 200I, 14:249-254.

\section{Pre-publication history}

The pre-publication history for this paper can be accessed here:

http://www.biomedcentral.com/1472-6955/5/7/prepub

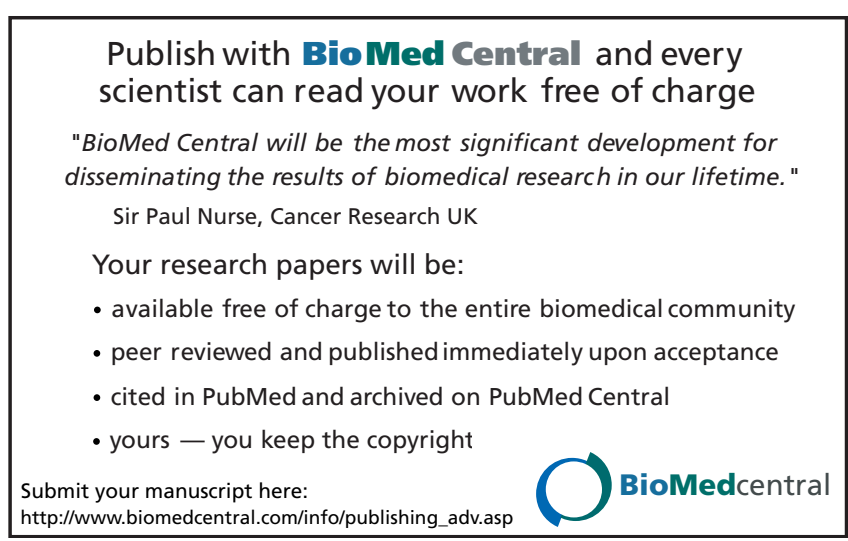

